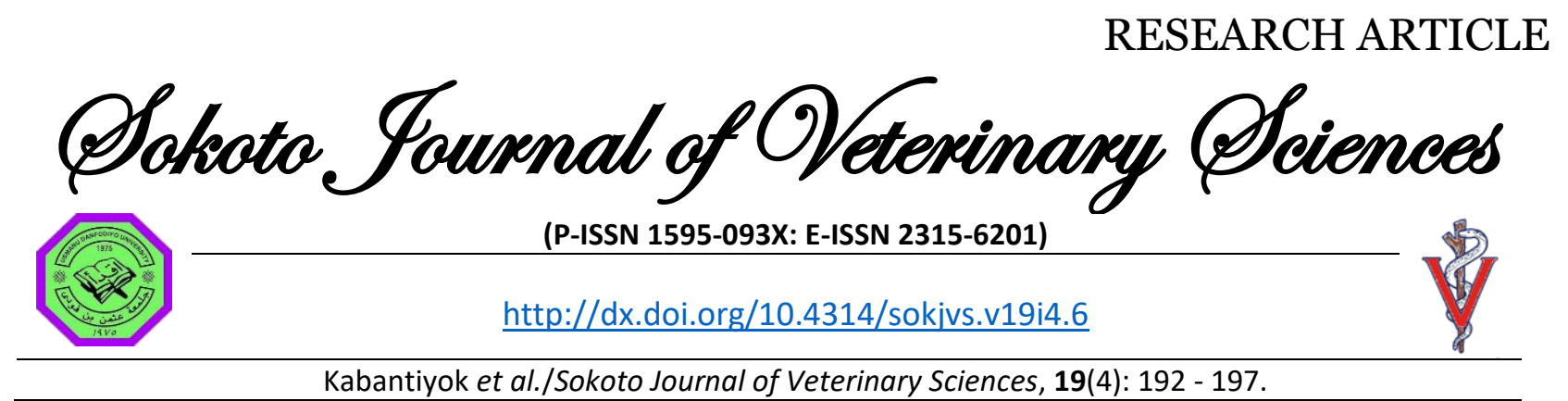

\title{
Footprints of swine influenza H1N1 and H3N2 in pigs from southern Kaduna, Nigeria
}

\author{
D Kabantiyok ${ }^{1 *}$, B Inuwa², JK Gyallak ${ }^{3}$, AJ Dadah4 , J Abraham-Oyiguh ${ }^{5}$, I \\ Shittu² \& CA Meseko ${ }^{5}$ \\ 1. Laboratory Diagnostic Services Division, National Veterinary Research Institute, PMB 01, Vom, Plateau \\ State, Nigeria \\ 2.Regional Laboratory for Animal Influenza Transboundary Animal Diseases, National Veterinary Research \\ Institute, PMB 01, Vom, Plateau State, Nigeria \\ 3.Quality Control Division, National Veterinary Research Institute, Vom Plateau State Nigeria. PMB 01, \\ Vom, Nigeria \\ 4.Department of Microbiology, Kaduna State University, Tafawa Balewa Way PMB 2339, Kaduna State, \\ Nigeria \\ 5. Department of Science Laboratory Technology, Federal Polytechnic Idah, PMB 1037, Idah, Kogi State, \\ Nigeria
}

*Correspondence: Tel.: +2347060975980; E-mail: denzelkbt@gmail.com

\begin{abstract}
Copyright: (c) 2021
Kabantiyok et al. This is an open-access article published under the terms of the Creative Commons Attribution License which permits unrestricted use, distribution, and reproduction in any medium, provided the original author and source are credited.
\end{abstract}

Publication History: Received: 0-04-2021

Revised: 14-08-2021

Accepted: 18-08-2021

\section{Abstract}

Influenza A virus presents a significant public health burden worldwide, with the 1918 Spanish flu pandemic being the most dramatic example. Swine influenza viruses can be transmitted to humans through occupational exposures and in live pig markets. Novel variants can emerge in pigs because they can be infected by human, avian and swine strains. This study was carried out to determine the seroprevalence and serotypes of swine influenza in pigs from a major slaughter slab in southern Kaduna. Using competitive ELISA and haemagglutination-inhibition (HI) assays, 305 swine sera were analysed. The result showed an overall seroprevalence of $28.20 \%(n=86)$, with H3N2 $7.87 \%(n=24)$ emerging as the most dominant subtype in circulation. Concurrent antibody detection of $\mathrm{H} 1 \mathrm{~N} 1$ in $5.26 \%(n=16)$ was also detected in boar $2.62 \%(n=8)$ and sows $2.62 \%(n=8)$. This study revealed swine Influenza H1N1 and H3N2 serotypes are in circulation in pigs in Kaduna State, and that reassortment in the instance of co-infection of swine host is possible.

Keywords: Co-seroprevalence, H1N1, H3N2, Serotypes, Swine Influenza, Kaduna 


\section{Introduction}

Influenza viruses (IVs) belong to a group of enveloped, single-stranded RNA viruses in the family of Orthomyxoviridae, which comprises of influenza $A, B$, and $C$ viruses (Tong et al., 2012), Thogoto virus, Dhori Thogoto virus, Salmon Isavirus, Quaranfil quaranja virus, and the recently distinguished Influenza D Virus (Hause et al., 2014; ICTV, 2020). Influenza A virus (IAV) is the causal agent of swine flu, a highly contagious respiratory disease of pigs (Sreta et al., 2007). Major subtypes of influenza $A$ virus in pigs include $\mathrm{H} 1 \mathrm{~N} 1, \mathrm{H} 1 \mathrm{~N} 2, \mathrm{H} 2 \mathrm{~N} 3, \mathrm{H} 3 \mathrm{~N} 1$, and $\mathrm{H} 3 \mathrm{~N} 2$. Influenza B virus (IBV) has not been isolated from swine because it is limited to human hosts (Koutsakos et al., 2016). However, medical history has recorded occasional IAV zoonotic transmissions between humans and pigs since the 1918 Spanish flu pandemic (Garten et al., 2009). It has since then been of public health significance because it undergoes mutations such as antigenic shift and antigenic drift (Willey et al., 2008). Because the respiratory epithelia of pigs express receptors for both avian type $(\alpha 2,3$ sialic acid) and swine type ( $\alpha 2,6$ sialic acid) influenza, they serve as significant hosts where new reassortants can emerge (Lowen \& Steel, 2014).

Despite the zoonotic and pre-pandemic susceptibility of some swine IAVs, knowledge of circulating viral subtypes in swine populations is minimal in some settings and even non-existent in several regions (Meseko et al., 2014). In 2006 Kaduna state became the epicentre of the first avian influenza outbreak in Nigeria (Joannis et al., 2006), and since then, several studies on influenza has focused on the virus in avian populations and equid carriers (Meseko et al., 2016). In some areas, such as Southern Kaduna, there is a scarcity of recent data for IAVs in swine. This study provides information that will help develop control measures to reduce public health risk and better understand the disease burden in pigs in Southern Kaduna.

We detected swine influenza $A$ antibodies by competitive ELISA and $\mathrm{H} 1$ and $\mathrm{H} 3$ by haemagglutination inhibition assay to assess joint seroconversion of positive cases from Southern Kaduna to ascertain the footprints of infections.

\section{Materials and Methods \\ Study area}

Southern Kaduna is known for subsistence backyard pig farming and pork consumption, as evidenced by the number of slaughter slabs and pork meat sellers. The Tunga Alade weekly pig market is located in Katsit Jema'a Local Government Area (Figure 1); a settlement on the outskirts of Kafanchan town is the largest pig market in Nigeria. The weekly pig market plays host to pig farmers from surrounding towns of Kwoi, Zonkwa, Manchok, Kagoro, and Kachia in the southern part of Kaduna State who buys and sell their livestock and has remained an important pig market centre since colonial days (Ajala et al., 2002).

\section{Sampling techniques/sample size}

The pigs used for this study were exsanguinated pigs sourced from LGAs in Southern Kaduna and brought to the Katsit Pig market slaughter slab. The pigs were selected randomly by convenience sampling weekly at the Pig market.

\section{Sample collection and processing}

A total of 305 swine sera were sampled for this study. $5 \mathrm{~mL}$ of blood was collected from exsanguinated pigs in plain sample bottles from December 2017 to June 2018 at the Katsit slaughter slab in Southern Kaduna. Sera samples were extracted from clotted blood into sterile tubes and transported on ice packs to the Regional Laboratory for Animal Influenza and other Transboundary Animal Diseases, National Veterinary Research Institute (NVRI), Vom for further analysis.

Enzyme-linked immunosorbent assay (ELISA) for detection of influenza $A$ antibody

Sera were mixed $(1 / 10)$ in dilute buffer (DB) before being assayed (e.g. by diluting $15 \mu \mathrm{L}$ of the sample with $13 \mu \mathrm{L}$ of $\mathrm{DB})$. The controls were not diluted. The test procedure was carried out according to the manufacturers' manual (IDEXX Laboratories, Inc. One

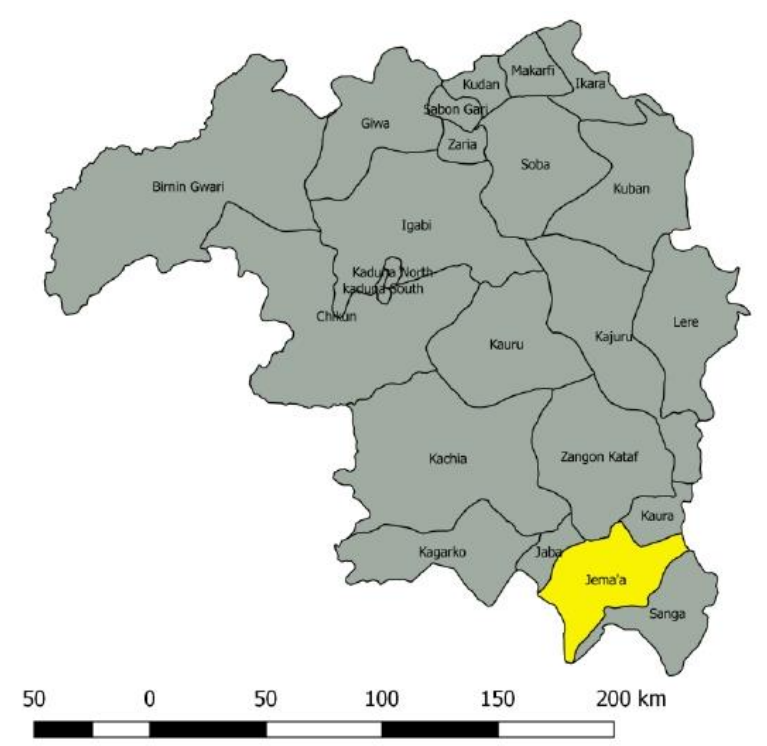

Figure 1: A map of Kaduna showing Jema'a Local Government Area, where the pig market is situated 
Drive Westbrook, Maine 04092 USA) and interpretation of the result was done according to the ELISA kit manual. All sera samples that tested positive to IAV and the positive reference antiserum for H1N1 and H3N2 were treated using Receptor Destroying Enzymes (RDE) before serotyping using an H1N1 and $\mathrm{H} 3 \mathrm{~N} 2$ reference antigen and antiserum using haemagglutination inhibition (HI) assay.

\section{Viral antigen and antiserum}

Swine Influenza antigens H1N1 and H3N2 with the corresponding antiserum were obtained from Instituto Zooprofilatticco Sperimentale delleVenezie (IZSVe) Legnaro, Italy and were used in the present study.

Influenza haemagglutination (HA) and haemagglutination inhibition assay

$\mathrm{HI}$ test was carried out to detect Swine Influenza Virus (SIV) antibodies against H1N1 and H3N2subtypes. Haemagglutination (HA) and Haemagglutination inhibition assays were performed following OIE Terrestrial Manual (OIE, 2018).

\section{Haemagglutination inhibition (HI) assay}

The $\mathrm{HI}$ assay was also conducted as described by the OIE (2018). A $25 \mu \mathrm{L}$ PBS was dispensed into each well of a plastic $\mathrm{V}$-bottomed microtitre plate, and $25 \mu \mathrm{L}$ of serum was later placed into the first well of each plate. Two-fold dilutions of $0.025 \mathrm{ml}$ volumes of the sera were made across the plate. $4 \mathrm{HAU}$ virus/antigen in $0.025 \mathrm{~mL}$ was added to each well, and the plate was left for $40 \mathrm{~min}$ at room temperature $\left(20^{\circ} \mathrm{C}\right)$. Later, $0.025 \mathrm{~mL}$ of $1 \%(\mathrm{v} / \mathrm{v})$ chicken red blood cells (RBCs) were added to each well and mixed gently, and the RBCs were allowed to settle to a distinct button for about $40 \mathrm{~min}$ at room temperature $\left(20^{\circ} \mathrm{C}\right)$. The Haemagglutination Inhibition (HI) titre was read from the highest dilution of serum, causing complete inhibition of $4 \mathrm{HAU}$ of antigen. The agglutination was assessed by tilting the plates. Only those wells in which the RBCs streamed at the same rate as the control wells (positive serum, virus/antigen and PBS controls) were considered to show inhibition. The validity of this result was assessed against a negative control. Serum titres greater than or equal to $1: 4$ $(2 \log 2)$ were considered positive. All data obtained were analysed using SPSS version 23.

\section{Results}

Out of 305 sera samples collected over four months, an overall prevalence of $28.20 \%(n=86)$ was recorded for Swine influenza A virus (Table 1). Monthly seroprevalence of $19.64 \%, 29.73 \%, 21.28 \%, 40.74 \%$ for December, January, February and June, respectively, were recorded in the study. The months of June and December had the highest and the least seroprevalence, respectively (Table 1). Serotyping of the ELISA positive SIV by HI test reveals H3N2 (7.87\%; $\mathrm{n}=24)$ serotype is more prevalent than $\mathrm{H} 1 \mathrm{~N} 1$ (5.25\%; $n=16$ ) (Table 2), with co-seroconversion of $2.62 \%$ $(n=8)$ in boars and $2.62 \%(n=8)$ in sows for H1N1 recorded. While H3N2 subtype seroprevalence of $3.61 \%(n=11)$ in boars and $4.26 \%(n=13)$ for sows was recorded (Table.2). Out of the total prevalence of 28.2 \% recorded, 5.25\% representing 16 Swine samples tested positive for $\mathrm{H} 1 \mathrm{~N} 1$ and $\mathrm{H} 3 \mathrm{~N} 2$ with the same values of $8(2.62 \%)$ observed for both males and females.

\section{Discussion}

The results of this study confirm the presence of Swine Influenza A virus, with a seroprevalence of $28.2 \%$ and an $\mathrm{H} 1$ and $\mathrm{H} 3$ co-seroconversion of $5.25 \%$ $(n=16)$ in pigs from the live animal market in Kaduna State. However, some limitations should be noted. Firstly, due to time constraints and available resources, the convenience sampling technique

Table 1: Monthly Seroprevalence of swine influenza A antibodies in southern Kaduna

\begin{tabular}{llllll}
\hline & Dec & Jan & Feb & Jun & Total \\
\hline Number of pigs sampled & 56 & 74 & 94 & 81 & 305 \\
Number positive & 11 & 22 & 20 & 33 & 86 \\
Percentage (\%) & 19.64 & 29.73 & 21.28 & 40.74 & 28.20 \\
\hline
\end{tabular}

Table 2: Distribution of swine influenza A serotypes based on sex and co-seroconversion

$\begin{array}{lccc}\text { Gender } & \text { H1N1 Subtype (\%) } & \text { H3N2 Subtype (\%) } & \text { Co-seroconversion (\%) } \\ \text { Male } & 8(2.62) & 11(3.61) & 8(2.62) \\ \text { Female } & 8(2.62) & 13(4.26) & 8(2.62) \\ \text { Total } & 16(5.25) & 24(7.87) & 16(5.25)\end{array}$


employed hinged on the assumption that as the largest pig market in the state, swine brought to the slabs were pooled from the communities of the surrounding Local Government Areas; as such, data collected may need to be replicated in future studies to minimise bias. Secondly, the sample size lacked enough power and so more study with a larger sample size might be needed to corroborate the findings of this study.

Most surveillance studies on swine influenza focus on H1N1 and H3N2 due to the fact that these two subtypes are often implicated in the ecology of swine influenza more than any other subtypes, and studies have shown that antibodies to the virus were detectable all year round, with peaks observed in the dry Harmattan seasons, from November to January and in April and May in Nigeria (David-West \& Cooke, 1974; Kabantiyok et al., 2019), which coincides with the period in which this study was carried out (Table 1). In a two-year surveillance study, Meseko et al. (2014) reported a prevalence of $13.7 \%$ of swine influenza $A$ in pigs from commercial piggery farms in Lagos state. When compared with the prevalence observed in this study, factors such as strict maintenance of biosecurity and good farm management could explain the reason for the sharp difference in the prevalence because the farms sampled are purely intensively managed. The prevalence $(28.2 \%)$ observed in this study means there is a high possibility of transmission between pig herds and humans living in a close association which is seen by the high prevalence reported by Adeola et al. (2010), who reported a prevalence of $68.3 \%$ among pig handlers.

Swine are cited as a major concern in the spread of novel IAVs to humans due to the expression of more $\alpha 2,6$-sialic acid (SA) receptors, which is shared in both the respiratory epithelia of swine and humans. The presence of antibodies to swine IAV means that subjects might have at one point or the other had direct contact with pigs because the virus has limited sustained human to human transmission history (Garten et al., 2009; Lewis et al., 2016; Kabantiyok et al., 2019).

Influenza A H1N1 and H3N2 viruses circulate widely among pigs and forms part of the dominant subtypes of Influenza virus infecting pigs (Kothalawala et al., 2006; Vincent et al., 2014). The findings of this study in Table 2 corroborate this as a high prevalence of $7.87 \%(n=24)$ for H3N2 and5.25\% ( $n=16)$ for H1N1 was observed. The H3N2 subtype is particularly known to circulate widely in pigs. It is antigenically related to the human type of influenza that is inclined to the procuring of internal protein genes from an avian virus. The literature on swine influenza is replete with data on the circulation of H1N1 and H3N2 in swine and human populations (Adeola et al., 2010; Odun-Ayo et al., 2018). Most studies show a higher H1N1 (Jolaoluwa et al., 2013) prevalence than for H3N2. The high prevalence of H3N2 in this study may reflect a shift in the dominant subtype among pigs in this region, although the antibody subtype in circulation is likely to be largely affected by the previous composition of vaccine (Choi et al., 2002) and for reasons unknown, the epidemiological status of certain SIV serotypes might vary from region to region (López-Robles et al., 2014). The former is ruled out as the government of Nigeria has always maintained a no influenza vaccine policy in livestock. More research into the epidemiological distribution of these subtypes in swine is required to better understand factors responsible for the variations of SIV subtypes in regions of unvaccinated swine populations.

This study recorded a $5.25 \% \quad(n=16)$ coseroconversion of H1N1 and H3N2s Table 2 . Concurrent infection of different strains in swine provides an enabling environment for reassortment, which may culminate in the emergence of new subtypes and even the potential for a recent pandemic outbreak. H3N2 is widespread in US swine, and this strain which has genes from human lineages, swine lineages, and avian lineages, was generated through reassortment (Pantin-Jackwood et al., 2014). Although this study limits itself to $\mathrm{H} 1 \mathrm{~N} 1$ and $\mathrm{H} 3 \mathrm{~N} 2$, there remain other subtypes that were not reported. Human interaction with pigs form dominant interface for the transfer of human type swine flu to pigs (Choi et al., 2002) as more human origin influenza viruses are responsible for the development of novel strain than avian origin influenza virus (Van Poucke et al., 2010) this could be attributed to the abundance of a2-6 SA linkages on the pigs' respiratory epithelia which is highly conserved for attachment to IAV of human origin. In a study on the prevalence of swine influenza virus subtypes on swine farms in the United States, Choi et al. (2002) reported a co-infection of $1.5 \%$ for $\mathrm{H} 1 \mathrm{~N} 1$ and H3N2 subtypes, which is lower than the $5.25 \%$ recorded in this study. The high value recorded in this study compared to the $1.5 \%$ recorded by Choi et al. (2002) could be accounted for because most swine used for this study are kept free-range where they interact with their environment and other pigs. Suriya et al. (2008), in a study to determine the risk factors associated with the influenza $A$ virus in 
pigs, recorded a very high co-seroconversion rate of $41.1 \%$.

Normally, the reassortment of gene segments between different subtypes of the virus plays an important role in the emergence of a novel strain. Coinfection sets the stage for it, and this process is highly efficient within a coinfected cell. Co-infection studies have shown that synchronous co-infection at moderate or high doses can give rise to $\sim 60$ to $70 \%$ of progeny shed from an animal host (Tao et al., $2015)$, so the presence of co-infection even as low as $5.25 \%$ is important in predicting the virus ecology. This study reveals a previous infection of swine influenza virus $\mathrm{H} 1 \mathrm{~N} 1$ and $\mathrm{H} 3 \mathrm{~N} 2$ subtypes in southern Kaduna. In addition, a concurrent seroconversion of $5.25 \%$ was also detected in boars and sows sampled. Therefore, we recommend more awareness to all pig stakeholders on the risk of the virus and surveillance to identify all the subtypes circulating in the area and the country at large to adopt suitable prevention and control measures.

\section{Conflict of Interest}

The authors declare that there is no conflict of interest.

\section{References}

Adeola OA, Adeniji JA \& Olugasa BO (2010). Detection of haemagglutination-inhibiting antibodies against human $\mathrm{H} 1$ and $\mathrm{H} 3$ strains of influenza A viruses in pigs in Ibadan, Nigeria. Zoonoses and Public Health, 57(7-8): 89-94.

Ajala MK \& Sanni SA (2002). Economics of Swine Marketing in Kafanchan (Katsit) Market, Jama'a Local Government Area of Kaduna State, Nigeria. Nigerian Journal of Animal Science, doi.10.5513/jcea.v8i3.469.

Choi YK, Goyal SM \& Joo HS (2002). Prevalence of swine influenza virus subtypes on swine farms in the United States. Archives of Virology, 147(6): 1209-1220.

David-West TS \& Cooke AR (1974). Laboratory and clinical investigation of the 1974 influenza epidemic in Nigeria. Bulletin of the World Health Organization, 51(1): 103.

Garten RJ, Davis CT, Russell CA, Shu B, Lindstrom S, Balish A \& Cox NJ (2009). Antigenic and genetic characteristics of swine-origin 2009 A (H1N1) influenza viruses circulating in humans. Science, 325(5937): 197-201.

Hause BM, Collin EA, Liu R, Huang B, Shen Z, Lu W \& Li F (2014). Characterisation of a novel influenza virus in cattle and swine: proposal for a new genus in the Orthomyxoviridae family. MBio, 5(2): e00031-14.

ICTV

https://talk.ictvonline.org/information/w/fa q/1323/how-to-cite-the-ictv-virustaxonomy, retrieved 12-2-2020

Joannis T, Lombin LH, De Benedictis P, Cattoli G \& Capua I (2006). Confirmation of H5N1 avian influenza in Africa. The Veterinary Record, 158(9): 309.

Jolaoluwa A E, Ogundipe G, Babalobi O \& Omilab S (2013). Prevalence and correlates of influenza-a in piggery workers and pigs in two communities in Lagos, Nigeria. Pan African Medical Journal, doi.10.11604/pamj.2013.16.102.1450.

Kabantiyok D, Abraham O \& Dadah AJ (2019). Seroprevalence of Swine Influenza A virus circulating in pigs from Southern Kaduna, Nigeria. Science World Journal, 14(3): 92-95.

Kothalawala H, Toussaint MJM, and Gruys E (2006). An overview of swine influenza. Veterinary Quarterly, 28(2): 45-53.

Koutsakos M, Nguyen T H, Barclay W S \& Kedzierska K (2016). Knowns and unknowns of influenza B viruses. Future Microbiology, 11(1): 119135.

Lewis NS, Russell CA, Langat P, Anderson TK, Berger K, Bielejec F \& Vincent AL (2016). The global antigenic diversity of swine influenza $A$ viruses. elife, 5: 12217.

López-Robles G, Montalvo-Corral M, Burgara-Estrella A \& Hernández J (2014). Serological and molecular prevalence of swine influenza virus on farms in northwestern Mexico. Veterinary Microbiology, 172(1-2): 323-328.

Lowen AC \& Steel J (2014). Roles of Humidity and Temperature in Shaping Influenza Seasonality. Journal of Virology, 88(14): 7692-7695.

Meseko C, Olaleye D, Capua I \& Cattoli G (2014). Swine influenza in sub-Saharan Africa Current knowledge and emerging insights. Zoonoses and Public Health, 61(4): 229-237.

Meseko CA, Ehizibolo DO, Nwokike EC \& Wungak YS (2016). Serological evidence of equine influenza virus in horse stables in Kaduna, Nigeria. Journal of Equine Science, 27(3): 99105.

Odun-Ayo F, Odaibo G \& Olaleye D (2018). Influenza virus $A(H 1$ and $H 3)$ and $B$ co-circulation among patient presenting with acute 
respiratory tract infection in Ibadan, Nigeria. African Health Sciences, 18(4): 1134-1143.

OIE (2018) World Organisation For Animal Health Manual of Diagnostic Tests and Vaccines for Pantin-Jackwood MJ, Miller PJ, Spackman E, Swayne DE, Susta L, Costa-Hurtado M \& Suarez DL (2014). Role of poultry in the spread of novel H7N9 influenza virus in China. Journal of Virology, 88(10): 5381-5390.

Sreta D, Kedkovid R, Tuamsang S, Kitikoon P \& Thanawongnuwech R (2007). Medical Microbiology, (JS Butel, SA Morse, editors). McGraw-Hill Publishing. Virology Journal, doi.10.1186/1743-422X-6-34.

Suriya R, Hassan L, Omar AR, Aini I, Tan CG, Lim YS \& Kamaruddin MI (2008). Seroprevalence and risk factors for influenza $A$ viruses in pigs in Peninsular Malaysia. Zoonoses and Public Health, 55(7): 342-351.

Tao H, Li L, White MC, Steel J \& Lowen AC (2015). Influenza A Virus Coinfection through Transmission Can Support High Levels of
Terrestrial Animals (Mammals, Birds and Bees) Office International des Epizooties. www.oie.int, retrieved 27-07-2019.

Reassortment. Journal of Virology, 89(16): 8453-8461.

Tong S, Li Y, Rivailler P, Conrardy C, Castillo DAA, Chen LM \& Donis RO (2012). A distinct lineage of influenza A virus from bats. In: Proceedings of the National Academy of Sciences, 109(11): 4269-4274.

Van Poucke SGM, Nicholls JM, Nauwynck HJ \& Van Reeth K (2010). Replication of avian, human and swine influenza viruses in porcine respiratory explants and association with sialic acid distribution. Virology Journal, doi.10.1186/1743-422X-7-38.

Vincent AL, Lager KM \& Anderson TK (2014). A brief introduction to influenza $A$ virus in swine. Humana Press, New York, NY. Pp 243-258.

Willey JM, Sherwood L \& Woolverton CJ (2008). Prescott, Harley, and Klein's Microbiology. New York: MacGraw-Hill. Pp 890-891. 